\title{
PHYTOCHEMICAL PROFILING, ANTIOXIDANT AND CARDIO- PROTECTIVE PROPERTIES OF PINOT NOIR CULTIVAR POMACE EXTRACTS
}

\author{
ŞTEFANIA SILVIA BALEA ${ }^{1}$, ALINA ELENA PÂRVU ${ }^{2 *}$, NASTASIA POP ${ }^{1}$, FERNANDO \\ ZAMORA MARÍN $^{3}$, ANDRA ANDREICUT, ${ }^{2}$, MARCEL PÂRVU $^{4}$ \\ ${ }^{I}$ Department of Horticulture and Landscaping, Faculty of Horticulture, University of Agricultural Sciences and Veterinary \\ Medicine, 3-5 Calea Mănăștur Street, Cluj-Napoca 400372, Romania \\ ${ }^{2}$ Department of Pathophysiology, Faculty of Medicine, "Iuliu Hațieganu" University of Medicine and Pharmacy, 4-6 Victor \\ Babeş Street, Cluj-Napoca 400012, Romania \\ ${ }^{3}$ Department of Biochemistry and Biotechnology, Faculty of Oenology, Rovira i Virgili University, C/Marcel.li Domingo s/n \\ Street, Tarragona 43007, Spain \\ ${ }^{4}$ Department of Biology, Faculty of Biology and Geology, “Babeș-Bolyai” University, 42 Republicii Street, Cluj-Napoca \\ 400015, Romania
}

*corresponding author: parvualinaelena@umfcluj.ro

Manuscript received: February 2018

\begin{abstract}
Fresh and fermented pomace extracts from Vitis vinifera L. Pinot noir were investigated. Total phenolic index, condensed tannins, total anthocyanins, proanthocyanidins, flavan-3-ol monomers, stilbenes and DPPH (2,2-diphenyl-1-picrylhydrazyl) free radical scavenger ability were measured. The effect of seven days pre-treatment on the isoprenaline-induced infarct-like lesion in rats was assessed by monitoring ECG and serum aspartate and alanine transaminase and creatine kinase. Oxidative stress was assessed by measuring serum total oxidative status, total antioxidant response, oxidative stress index, malondialdehyde, total thiols and nitric oxide. The extracts had high phenolic content and antioxidant activity. Both extracts improved ECG changes, cardiac markers and oxidative stress. In conclusions, fresh and fermented Pinot noir pomace extracts were cardio-protective by reducing oxidative stress.
\end{abstract}

\section{Rezumat}

$\mathrm{Au}$ fost evaluate extractele proaspete și fermentate din tescovină de stuguri Pinot noir. A fost efectuată analiza fitochimică şi s-a determinat activitatea antioxidantă in vitro cu DPPH (2,2-difenil-1-picrilhidrazil). Efectul pre-tratamentului de şapte zile asupra infarctului miocardic acut indus cu izoprenalină la şobolani a fost evaluat prin ECG şi prin monitorizarea nivelurilor serice de transaminaze și creatin-kinază. Stresul oxidativ a fost evaluat prin determinarea serică a statusului oxidativ total, reactivităţii antioxidante totale, a indexului stresului oxidativ, a malondialdehidei, a tiolilor totali și a oxidului nitric. Ambele extracte au avut un conținut ridicat de polifenoli și activitate antioxidantă in vitro. Extractele au îmbunătățit modificările ECG, biomarkerii cardiaci și stresul oxidativ. În concluzie, extractele de tescovină de Pinot noir au avut efect cardioprotector prin reducerea stresului oxidativ.

Keywords: Pinot noir, grape pomace, polyphenols, antioxidant, cardio-protective

\section{Introduction}

Grape pomace (GP) is the residue of winemaking process. It is an important ecological and economical waste management problem because it represents about $20 \%$ of the weight of processed grapes [1]. It consists of skin, stem, residual pulp and seed. GP is used mainly for animal feed, organic fertilizers, ethanol production, or is direct disposed as a waste [2]. Due to the incomplete extraction during winemaking process, fermented GP contains significant amounts of bioactive components such as polyphenols. About $70 \%$ phenolic compounds were reported to remain in the pomace [3]. Polyphenols contained in grapes and wine have been classified into two main groups: non-flavonoids (hydroxybenzoic and hydroxycinnamic acids and their derivatives, stilbenes and 65 phenolic alcohols) and flavonoids (anthocyanins, flavanols, flavonols and dihydroflavonols) [4]. In GP the most abundant polyphenols are anthocyanins, flavanols, flavonols, hydroxybenzoic and hydroxycinnamic acids and stilbenes [5]. This makes GP a potential source of phytochemicals that may be used as functional compounds for the pharmaceutical, cosmetic and food industries [1]. Information concerning the fresh GP phytochemical composition and biological effects is scarce.

Polyphenols have health-promoting effects mainly due to their powerful antioxidant activity [6]. Oxidative stress is a state in which excess reactive oxygen 
species (ROS) overwhelm endogenous antioxidant systems [7]. In the last decades oxidative stress has been proposed as an essential mechanism in the pathophysiology of chronic diseases, such as atherosclerosis, cardiovascular disease, type 2 diabetes [8, 9], neural disorders, and cancer [10]. In Myocardial infarction (MI), reactive oxygen species (ROS) are the primary components of oxidative damage of cardiomyocytes. Thus, much research has been devoted to studying the role of antioxidants in preventing MI. Natural antioxidants contribute to the protection of cells and tissues against oxidative stress induced by ROS, reactive nitrogen species (RNS) and other free radicals. Consumption of products with high polyphenol content is associated with important reduction of cardiovascular disease risk factors [11]. Furthermore, in cardiovascular pathophysiology, oxidative stress became not just an important therapeutic target but also a disease biomarker $[12$, 13].

Phenolic composition is highly dependent on geographical location, weather conditions, winemaking technology and grape variety. Consequently, there are also differences regarding the GP antioxidant properties [14]. Currently, no study is available concerning the phyto-chemistry and biological effects of the GP from cv. Pinot noir cultivated in Romania. The aims of this work were to assess the phenolic composition, the antioxidant activity and cardioprotective effects of the fresh and fermented Pinot noir GP cultivated in Romania.

\section{Materials and Methods}

\section{Chemicals and reagents}

All solvents were of HPLC quality, and all chemicals were of analytical grade ( $>99 \%$ ). Methanol, ethanol (96.5\%), deionised water, acetonitrile, formic acid, absolute ethanol and hydrochloric acid (37\%) were purchased from Panreac (Barcelona, Spain). The commercial standards trans-resveratrol, trans-piceid and (-)-epicatechin were bought from Phytolab (Vestenbergsgreuth, Germany) and Extrasynthese (Genay, France), respectively. By UV irradiation (366 nm light for $5 \mathrm{~min}$ in quartz vials), $25 \%$ $\mathrm{MeOH}$ solutions of the trans isomers of resveratrol and piceid (resveratrol-3-glucoside) were transformed into their respective cis isomers. Trolox (6-hydroxy2,5,7,8-tetramethylchroman-2-carboxylic acid), N(1-Naphthyl) ethylenediamine dihydrochloride, xylenol orange [o-cresolsulfonphthalein-3,3- bis(sodium methyliminodiacetate)], ortho dianisidine, vanadium (III) chloride, hydrogen peroxide, methanol, diethyl ether sulphanilamide and ferrous ammonium sulphate, thiobarbituric acid, trichloroacetic acid, ethylenediaminetetraacetic acid, sodium dodecylsulphate, butylated hydroxytoluene, 1,1,3,3-tetraethoxypropane, 5,5'-dithiobis-(2-nitrobenzoic acid), glutathione were purchased from Sigma-Aldrich (Germany) and Merck (Germany).

Grape sample

The grape Vitis vinifera L. Pinot noir (clone 0828, Vitis L., port graft: S.O.4, France) cultivated in 2006, in Romania, Mureș County, Mica parish, part of Târnavelor Plateau (46² $21^{\prime} 44.5^{\prime \prime} \mathrm{N}$ and $24^{\circ} 23^{\prime} 55.7^{\prime \prime E}$; 330 - $350 \mathrm{~m}$ above sea level), was used in our studies. Grapes were harvested manually at full maturity level, during the 2015 vintage. The GP samples were collected in two winemaking stages: one was supplied immediately after pressing the grapes, the fresh unfermented GP (PNFs), and the other was supplied after 20 days of fermentation at $20^{\circ} \mathrm{C}$, the fermented GP (PNFr). The samples were stored in vacuum bags at $-22^{\circ} \mathrm{C}$ prior the analysis and use in the experiments.

Grape pomace samples preparation for phytochemical analysis

The GPs were submitted to the freeze-drying process and then ground with a domestic blender (Sinbo, model NO.: SCM 2923) for 5 minutes. Because polyphenolic compounds extraction in hydroalcoholic solutions has a higher efficiency [15] in our study water-ethanol mixture was applied. The extracts were prepared by adding $50 \mathrm{~mL}$ of $50 \%$ ethanol and $1 \mathrm{~mL}$ of $5.25 \%$ metabisulphite (MBS) to $5 \mathrm{~g}$ of GP sample. All extracts were placed in a water bath at $50^{\circ} \mathrm{C}$ for 7 days and stirred daily. Prior to each analysis the extracts were centrifuged, and the supernatants were further used. The procedure was repeated 3 times for each sample.

Phytochemical analysis

Total phenolic index, condensed tannins and total anthocyanins determination

The total phenolic index (TPI) was spectrophotometrically measured as previously reported [16]. The condensed tannin concentration (CT) was estimated by precipitation with methyl-cellulose as previously reported [17]. Aqueous (-)-epicatechin solutions were used as standard for TPI and TC. The total anthocyanin content (TAC) was determined spectrophotometrically as previously reported with malvidin3-O-glucoside chloride as standard [18]. Spectrophotometric measurements for TPI, TT and TAC were performed with a Helios Alpha UV-Vis spectrophotometer Thermo Fisher Scientific Inc., Waltham, MA, USA.

HPLC-DAD determination of proanthocyanidins and flavan-3-ol monomers

The proanthocyanidins of the GP were extracted and analysed by acid depolymerization in the presence of an excess of phloroglucinol [19]. The products of the reaction were separated by RP-HPLC-DAD. The proanthocyanidins were analysed with an Agilent 1200 Series HPLC equipped with a G1362A refractive index detector (RID), a G1315D DAD, a 
FARMACIA, 2018, Vol. 66, 3

G1311A quaternary pump, a G1316A column oven and a G1329A autosampler (Agilent Technologies, Santa Clara, CA, USA). The chromatographic system was managed by an Agilent Chem Station (version B.01.03) data processing station. The number of terminal subunits was considered to be the difference between the total monomers measured in normal conditions (with phloroglucinol) and thus obtained when the analysis was performed without phloroglucinol addition. The number of extension subunits was considered as the addition of all the phloroglucinol adducts. Because acid catalysis with phloroglucinol is not completely efficient, the real yield of the reaction was measured using a pure B2 proanthocyanidin dimer [(-)-epicatechin-(4 $\rightarrow 8)$-(-)-epicatechin]. This output was used to calculate the total proanthocyanidin concentration from extracts.

The mean degree of polymerization $(\mathrm{mDP})$ and the percentage of prodelphinidins (PD \%) the percentage of galloylation $(\mathrm{G} \%)$ were calculated after previously described methods [19]. In order to quantify the flavan-3-ol monomers, $(+)$-catechin, ()-epicatechin, and (-)-epicatechin-3-O-gallate in GP, the assay was also carried out without the addition of phloroglucinol and the retention times were compared with those of pure compounds. All analysis were repeated three times.

HPLC-DAD-ESI-MS/MS determination of stilbenes HPLC identification of GP stilbenes was performed using an Agilent 1200 series system equipped with DAD (Agilent, Germany) and coupled to an AB Sciex 3200 Q TRAP (Applied Biosystems) electrospray ionization mass spectrometry system (ESI-MS/MS) [20]. A validated method already published was used [21]. The chromatographic system was managed by an Agilent Chem Station (version B.01.03) data-process in $G$ station. The mass spectral data were processed with Analyst MDS software (Applied Bio-systems, version 1.5).

In vitro antioxidant activity

Free radical scavenging activity (RSA) was assessed by the DPPH assay based on the previously described method [22]. The following equation was used to determine the percentage of the RSA of each extract:

$$
\operatorname{RSA}(\%)=\left[1-\left(\mathrm{A}_{\text {sample }}-\mathrm{A}_{\text {blank }}\right) / \mathrm{A}_{\text {control }}\right] \times 100,
$$

where, $A_{\text {control }}$ is the absorbance of DPPH radical + methanol, $A_{\text {sample }}$ is the absorbance of DPPH radical + sample, and $A_{\text {blank }}$ is the absorbance of methanol + sample. Antiradical activity was defined as the amount of antioxidant necessary to decrease the initial DPPH concentration by $50 \%\left(\mathrm{EC}_{50}\right) . \mathrm{EC}_{50}$ was calculated with Trolox (TE) as equivalent. An $\mathrm{IC}_{50}<50 \mu \mathrm{g} \mathrm{TE} / \mathrm{mL}$ shows a very good antioxidant activity; an $\mathrm{IC}_{50}$ of $50-100 \mu \mathrm{g} \mathrm{TE} / \mathrm{mL}$ means a good antioxidant activity; an $\mathrm{IC}_{50}$ of $100-200 \mu \mathrm{g}$ $\mathrm{TE} / \mathrm{mL}$ shows a weak antioxidant activity; an $\mathrm{IC}_{50}>$
$200 \mu \mathrm{g}$ TE/mL means no antioxidant activity. The assay was performed in triplicate.

Plant extracts preparation for in vivo study

Pinot noir fresh GP extract (PNFs) and Pinot noir fermented GP extract (PNFr) were obtained with 70\% ethanol (Merck, Bucharest, Romania) by a modified Squibb re-percolation method $(1 / 1 \mathrm{~g} / \mathrm{mL})$ [23].

\section{In vivo study}

Animals

The experiments were carried out on male Wistar rats, weighing $200-250 \mathrm{~g}$, that were bred in the Animal Facility of "Iuliu Hațieganu" University of Medicine and Pharmacy, Cluj-Napoca, Romania. The animals ( $n=5 /$ group) were housed in standard polypropylene cages under controlled conditions (12 $\mathrm{h}$ light/dark cycle, at an average temperature of $21-22^{\circ} \mathrm{C}$ ), and with ad libitum access to standard pellet diet (Cantacuzino Institute, Bucharest, Romania) and water.

Experimental protocols have been approved by the Ethics Committee (no. 26/16.12.2015) of the University of Agricultural Sciences and Veterinary Medicine from Cluj-Napoca, Romania.

The animals were allowed 3 days for acclimatization in the housing facility. At the end of the experiments under anaesthesia with ketamine $(60 \mathrm{mg} / \mathrm{kg} \mathrm{bw})$ and xylazine (15 mg/kg bw) [23] blood was withdrawn by retro-orbital puncture, serum was separated and stored at $-80^{\circ} \mathrm{C}$ until use, and then animals were killed by cervical dislocation.

Experimental myocardial ischemia

The animals were divided into 4 groups $(n=5)$. The negative control group (CONTROL) and the isoprenaline-induced (ISO) myocardial infarction group received $0.9 \%$ saline $(1 \mathrm{~mL} /$ day p.o.) for 7 days. In PNFs and PNFr groups each extract was administrated orally by gavage $(1 \mathrm{~mL} /$ day p.o.) for 7 days. In day 8 and day 9 rats were injected with ISO dissolved in normal saline $(150 \mathrm{mg} / \mathrm{kg}$, s.c. $)$ at an interval of $24 \mathrm{~h}$ to induce experimental MI, except for the CONTROL group. ECG was recorded in day one, 7, and 10 . In day 10, after ECG registration, blood samples were collected for estimation of cardiac and oxidative stress biomarkers.

\section{Electrocardiography}

The overnight-fasted rats were anaesthetized with ketamine and xylazine. At 15 min after anaesthesia animals were placed in the supine position on a board, electrodes were bound on the paw pads of each rat, and ECG was recorded from the limb lead at position II (right forelimb to left hind limb) with a Biopac MP150 system. The ECG apparatus was calibrated at $1 \mathrm{mV} / 1 \mathrm{~cm}$ with speed of $50 \mathrm{~mm} / \mathrm{s}$. Analysis of ECG waves was done to calculate heart rate (HR) (beats/min), RR intervals (msec), QT interval $(\mathrm{msec})$ and ST segment changes $(\mathrm{mV})$. QT interval 
was measured from the beginning of QRS complex to the end of $\mathrm{T}$ wave and it was calculated in msec. Corrected QT interval (QTc), which is used to rectify the influence of the heart rate on QT interval, was also calculated according to Bazett formula: QT interval divided by the square root of RR interval [24].

Cardiac biomarkers

The creatine kinase-MB (CK-MB), aspartate transaminase (AST) and alanine transaminase (ALT) activities were measured by using commercial kits. Antioxidant biomarkers

The total oxidative status (TOS) of the serum was measured using a colorimetric assay [25]. Assay measurements were standardized using hydrogen peroxide $\left(\mathrm{H}_{2} \mathrm{O}_{2}\right)$ as the oxidative species, and the assay results were expressed in $\mu \mathrm{mol} \mathrm{H}_{2} \mathrm{O}_{2}$ Equiv/L. The total antioxidant response (TAR) was measured in serum using a colorimetric assay [26]. This assay is calibrated using Trolox and results were expressed as mmol Trolox Equiv/L.

The ratio of the TOS to the TAR represents the oxidative stress index (OSI), an indicator of the degree of oxidative stress: OSI (Arbitrary Unit) = TOS (mol H $\mathrm{O}_{2}$ Equiv/L)/TAR (mmol Trolox Equiv/L) [27].

Malondialdehyde (MDA) was assessed as a lipid peroxidation marker, using thiobarbituric acid, as previously described [28]. The absorbance of the supernatant was measured at $532 \mathrm{~nm}$. A standard curve was generated with a 1,1,3,3-tetraethoxypropane standard $(0.3-10 \mathrm{nmol} / \mathrm{mL})$. Serum MDA concentration was expressed as $\mathrm{nmol} / \mathrm{mL}$ of serum.

Total thiols ( $\mathrm{SH})$ were estimated using Ellman's reagent [23]. Supernatant absorbance was measured at $412 \mathrm{~nm}$. To create a standard curve, solutions of glutathione (GSH) ranging from 0.25 to $2 \mathrm{mM} \mathrm{GSH}$ were used. Serum SH concentration was expressed as mmol $\mathrm{GSH} / \mathrm{mL}$.

The Griess reaction was used to indirectly determine NO synthesis by measuring total nitrates and nitrites
(NOx). Firstly serum proteins were removed by extraction with a $3: 1(\mathrm{v}: \mathrm{v})$ solution of methanol/diethyl ether. The sample absorbance was read at $540 \mathrm{~nm}$. The concentration of serum NOx was determined using a sodium nitrite-based curve and expressed as $\mu \mathrm{mol} / \mathrm{L}$ nitrite [29].

All spectrophotometric measurements were performed using a Jasco V-530 UV-Vis spectrophotometer (Jasco International Co., Ltd., Tokyo, Japan).

Statistical analysis

All statistical analyses were performed by SPSS (v20.0) software. Results were expressed as means \pm standard deviations. Data were compared by oneway ANOVA and post hoc Bonferroni-Holm test. Pearson's correlation coefficient was used to evaluate the relationships between parameters of the same group. The level of significance was set at $p<0.05$.

\section{Results and Discussion}

Total phenolic index, condensed tannins and total anthocyanin content

The TPI, CT and TAC obtained from Pinot noir GP are shown in Table I. In the present study, PNFr pomace had significantly higher polyphenols extraction than PNFs $(\mathrm{p}<0.05)$, and higher CT in PNFs than in PNFr, the difference being significant $(\mathrm{p}<0.01)$. TAC was higher in PNFs than in PNFr. Statistical difference between the two samples TAC was also significant $(\mathrm{p}<0.01)$.

HPLC-DAD determination of proanthocyanidins and flavan-3-ol monomers

GP proanthocyanidins analysis is shown in Table I. Results indicated that in PNFr total proanthocyanidins concentration was almost similar to that from PNFs $(p>0.05)$. As shown in Table I, the $\mathrm{mDP}$ of PNFr was higher than in PNFs $(p<0.05)$; PD\% was no significantly different $(\mathrm{p}>0.05)$, between PNFs and PNFr and the G\% in PNFr was higher than in PNFs $(p<0.05)$.

Table I

Phytochemical analysis of grape pomaces of Pinot noir 2015 from Mica parish, Romania

\begin{tabular}{|c|c|c|c|c|c|}
\hline Type of GP & \multicolumn{2}{|c|}{ TPI (mg catechin equivalent/g d.w.) } & \multicolumn{2}{|c|}{ CT (mg epicatechin/g d.w.) } & TAC (mg malvidin-3-O-glucoside /g d.w.) \\
\hline PNFs & $110.99 \pm 4.17$ & & 60.35 & \pm 9.22 & $80.95 \pm 20.94 * *$ \\
\hline PNFr & $139.08 \pm 2.78 *$ & & $93.41=$ & $\pm 1.34 * *$ & $22.21 \pm 0.88$ \\
\hline \multicolumn{2}{|c|}{ proanthocyanidins $(\mathrm{mg} / \mathrm{g}$ d.w.) } & \multicolumn{2}{|c|}{ mDP } & PD\% & $\mathbf{G \%}$ \\
\hline PNFs & $28.29 \pm 3.03$ & & $\pm 0.51^{*}$ & $2.47 \pm 0.09$ & $14.04 \pm 1.00$ \\
\hline \multirow{2}{*}{ PNFr } & $28.65 \pm 2.68$ & & \pm 1.67 & $3.74 \pm 0.51$ & $16.15 \pm 0.31^{*}$ \\
\hline & flavan-3-ol monomers (mg/g d.w.) & \multicolumn{2}{|c|}{$(+)$-catechin (mg/g d.w.) } & \multicolumn{2}{|c|}{ (-)-epicatechin (mg/g d.w.) epicatechin-3-O-gallate (mg/g d.w.) } \\
\hline PNFs & $5.44 \pm 1.18^{*}$ & & $9 \pm 0.78$ & $1.85 \pm 0.38$ & $0.10 \pm 0.02$ \\
\hline \multirow{2}{*}{ PNFr } & $3.85 \pm 0.13$ & & $3 \pm 0.09$ & $1.17 \pm 0.04$ & $0.05 \pm 0.00$ \\
\hline & -resveratrol ( $\mu \mathrm{g} / \mathrm{g}$ d.w.) & cis-resver: & trol $(\mu \mathrm{g} / \mathrm{g}$ d.w. $)$ & trans-piceid $(\mu \mathrm{g} / \mathrm{g}$ d.w.) & cis-piceid $(\mu \mathrm{g} / \mathrm{g} \mathrm{d.w.)}$ \\
\hline PNFs & $7.54 \pm 0.31$ & 74.97 & $\pm 5.05 * * *$ & $270.12 \pm 19.58^{* * *}$ & $146.75 \pm 8.04 * * *$ \\
\hline PNFr & $7.88 \pm 2.67$ & 11. & $6 \pm 0.52$ & $43.76 \pm 3.40$ & $18.81 \pm 1.47$ \\
\hline
\end{tabular}

The flavan-3-ol monomers from the GP from cv. Pinot noir were described in Table I. With respect to the total flavan-3-ol monomers concentration, we found that it was higher in the PNFs sample than in 
FARMACIA, 2018, Vol. 66, 3

the PNFr sample $(\mathrm{p}<0.01)$. Individual flavan-3-ol monomers analysis revealed that there were no significant differences of (+)-catechin, (-)-epicatechin and epicatechin-3-O-gallate concentration in the PNFs and PNFr $(\mathrm{p}>0.05)$.

HPLC-DAD-ESI-MS/MS determination of stilbenes The trans-resveratrol concentration was found to be almost similar in the PNFs and PNFr $(\mathrm{p}>0.05)$. Cisresveratrol was in a higher amount in PNFs $(p<0.001)$ than in PNFr. In both PNFs and PNFr, piceid were the most abundant stilbenes and both isomers cis- and trans-piceid were in a greater quantity in the PNFs samples as compared to the PNFr samples $(\mathrm{p}<0.001)$ (Table I).

DPPH Radical scavenging activity (DPPH RSA)

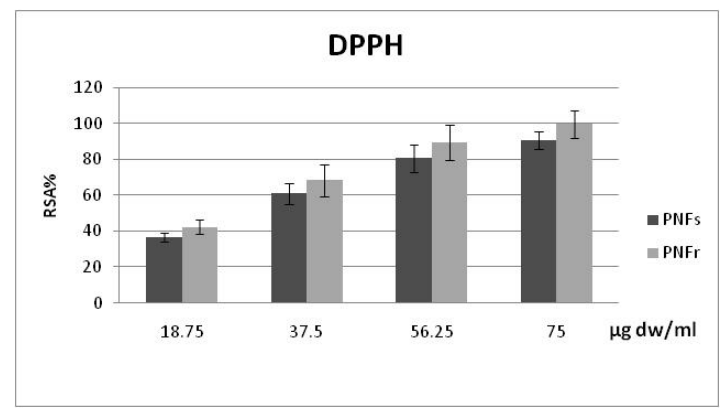

Figure 1.

DPPH radical scavenging activity of grape pomaces of Pinot noir

$(\mathrm{PNFs}=$ fresh Pinot noir grape pomace extract $\mathrm{PNFr}=$ fermented Pinot noir grape pomace extract; RSA $\%=$ radical scavenging activity)

The PNFs and PNFr showed very good DPPH RSA (Figure 1): the PNFr exhibit a better antioxidant activity $\left(\mathrm{IC}_{50}=29.58 \mu \mathrm{g} \mathrm{TE} / \mathrm{mL}\right)$ than PNFs $\left(\mathrm{IC}_{50}=29.06 \mu \mathrm{g}\right.$ $\mathrm{TE} / \mathrm{mL}$ ), but there was no statistically significant difference between the extracts $(p>0.05)$. For PNFs

DPPH test results exhibited significant, positive correlations with $\mathrm{CT}$, TAC, flavan-3-ols monomers and stilbenes results $(\mathrm{r}=0.80-0.99)$. The PNFr DPPH test correlated with proanthocyanidins, PD, $\mathrm{mDP}$ and cis- stilbenes $(\mathrm{r}=0.76-0.90)$.

Effect of Pinot noir grape pomace extracts on ECG parameters

The ECG patterns of control and experimental group rats are shown in Figure 2 and Table II. Isoprenaline (ISO) induced infarct-like lesion was represented by ST segment depression, T wave inversion, QT and QTc intervals increase. Pre-treatment with PNFs and PNFr had no significant effects on RR, HR, QT and QTc intervals, but resulted in a reduction in the ST segment depression as compared to the ISO group.

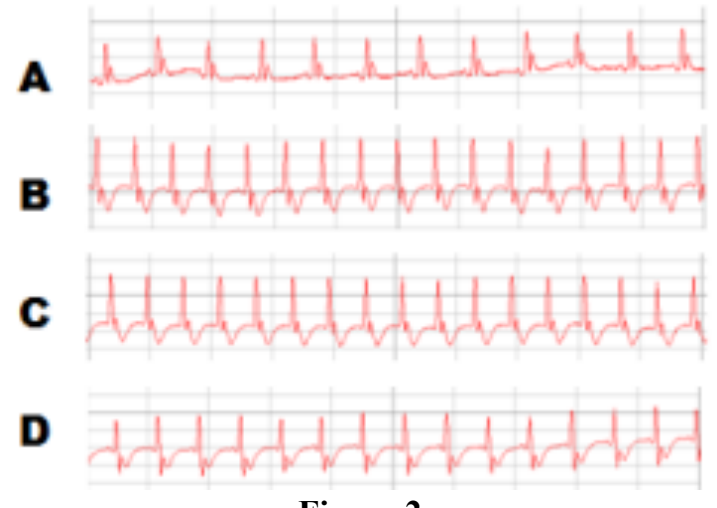

Figure 2.

Chart records showing the effect of grape pomaces of Pinot noir 2015 from Mica parish Romania on ECG tracings: (A) control; (B) fresh Pinot noir grape pomace extract; (C) fermented Pinot noir grape pomace extract; (D) isoproterenol. Electrocardiogram was recorded from limb leads II in each group. The sensitivity was $1 \mathrm{mV}$ and chart speed was $50 \mathrm{~mm} / \mathrm{sec}$.

Table II

Effects of grape pomaces of Pinot noir 2015 from Mica parish Romania on RR interval, QT interval, QTc, heart rate and $\mathrm{ST}$ segment of rats ECG

\begin{tabular}{lccccc}
\hline & RR $(\mathrm{ms})$ & QT $(\mathrm{ms})$ & QTc $(\mathrm{ms})$ & HR $(\mathrm{bpm})$ & ST $(\mathrm{mV})$ \\
\hline CONTROL & $248 \pm 22.80$ & $108 \pm 10.95$ & $216 \pm 18.16$ & $229.84 \pm 39.97$ & 0 \\
ISO & $256 \pm 21.90^{*}$ & $136 \pm 16.71^{* *}$ & $274 \pm 43.35^{* *}$ & $235.71 \pm 19.55$ & $0.54 \pm 0.01^{* *}$ \\
PNFs & $264 \pm 32.86$ & $138 \pm 10.90$ & $278 \pm 24.90$ & $229.80 \pm 25.53$ & $0.13 \pm 0.01^{\# \#}$ \\
PNFr & $258 \pm 17.88$ & $136 \pm 16.73$ & $276 \pm 33.61$ & $244.54 \pm 22.12$ & $0.21 \pm 0.01^{\#}$ \\
\hline
\end{tabular}

Data are expressed as mean \pm SEM, $\mathrm{n}=6 .{ }^{*} \mathrm{p}<0.05,{ }^{* *} \mathrm{p}<0.01 v s$. control group; ${ }^{\#} \mathrm{p}<0.05,{ }^{\# \#} \mathrm{p}<0.01 v s$. ISO group; PNFs $=$ fresh Pinot noir grape pomace extract; $\mathrm{PNFr}=$ fermented $\mathrm{Pinot}$ noir grape pomace extract; $\mathrm{ISO}=$ isoprenaline

Effect of Pinot noir grape pomace extracts on cardiac enzymes

The cardio-protective effects of Pinot noir GP extracts revealed by the serum cardiac marker enzyme AST, ALT, and CK-MB levels are summarized in Table III. ISO-treated alone caused significant increase of the serum cardiac enzymes levels $(p<0.001)$ as compared to normal control rats. Pre-treatment with
PNFs and PNFr extracts significantly reduced AST $(\mathrm{p}<0.01)$, ALT $(\mathrm{p}<0.01)$ and CK-MB $(\mathrm{p}<0.001)$ (Table III). In ISO-treated group ST depression correlated well with the increase of AST, ALT and CK-MB. The effects of PNFs and PNFr on cardiac enzymes were also correlated with ST segment changes. 
Table III

Effect of grape pomaces of Pinot noir 2015 from Mica parish Romania on serum cardiac damage markers

\begin{tabular}{lccc}
\hline & AST (UI/L) & ALT (UI/L) & CK-MB (UI/L) \\
\hline CONTROL & $51.36 \pm 7.04$ & $47.27 \pm 3.17$ & $213.10 \pm 46.48$ \\
ISO & $131.50 \pm 20.72^{* * *}$ & $113.27 \pm 13.17^{* * *}$ & $562.50 \pm 105.20^{* * *}$ \\
PNFs & $98.52 \pm 8.18^{\# \#}$ & $86.00 \pm 8.14^{\# \#}$ & $375.30 \pm 33.61^{\# \#}$ \\
PNFr & $103.73 \pm 9.34^{\# \#}$ & $86.74 \pm 5.59^{\# \#}$ & $295.20 \pm 66.49^{\# \# \#}$ \\
\hline
\end{tabular}

Data are expressed as mean $\pm \operatorname{SEM}(\mathrm{n}=6),{ }^{* * *} \mathrm{p}<0.001 v s$. control; ${ }^{\#} \mathrm{p}<0.05,{ }^{\# \#} \mathrm{p}<0.01 v s$. ISO group. AST $=$ aspartate transaminase; $\mathrm{ALT}=$ alanine transaminase; $\mathrm{CK}-\mathrm{MB}=$ creatine kinase-MB; PNFs $=$ fresh Pinot noir grape pomace extract; $\mathrm{PNFr}=$ fermented Pinot noir grape pomace extract; ISO = isoprenaline.

Effect of Pinot noir GP extracts on in vivo isoprenalineinduced nitro-oxidative stress

Serum OSI increased significantly $(\mathrm{p}<0.001)$ in ISOinduced ischemia by increasing TOS $(\mathrm{p}<0.001)$ and reducing TAR $(\mathrm{p}<0.01)$. The pre-treatment with PNFs and PNFr significantly reduced OSI $(\mathrm{p}<0.001)$ by lowering TOS $(\mathrm{p}<0.001)$, and increasing TAR $(p<0.01)$ (Table IV). Furthermore, OSI, TOS and TAR changes were correlated.

ISO-induced ischemia was associated with a significant increase of MDA ( $<<0.01)$, and PNFs and PNFr pre-treatments reduced that response $(p<0.05)$. PNFs and PNFr were equally efficient on MDA $(p>0.05)$ (Table IV).

SH was reduced in ISO group, but the effect was not significant $(p>0.05)$. Pre-treatment with PNFs and PNFr had no important influence on $\mathrm{SH}$ concentration $(p>0.05)$ (Table IV).

Serum NOx was significantly elevated by ISO administration $(\mathrm{p}<0.001)$ compared to the control rats. Pre-treatment of rats with PNFs and PNFr extracts caused no significant changes $(\mathrm{p}>0.05)$ (Table IV).

Table IV

Effect of grape pomaces of Pinot noir 2015 from Mica parish Romania on serum oxidative stress markers

\begin{tabular}{lcccccc}
\hline Type of GP & TOS $\left(\mu \mathrm{M} \mathrm{H}_{2} \mathrm{O}_{2}\right.$ equiv/L) & $\begin{array}{c}\text { TAR }(\mathrm{mM} \text { Trolox } \\
\text { equiv/L) }\end{array}$ & OSI & MDA $(\mathrm{nM} / \mathrm{L})$ & $\mathrm{SH}(\mathrm{mM} / \mathrm{L})$ & $\mathrm{NOx}(\mu \mathrm{M} / \mathrm{L})$ \\
\hline $\mathrm{CONTROL}$ & $26.92 \pm 10.30$ & $1.090 \pm 0.001$ & $0.25 \pm 0.02$ & $1.09 \pm 0.22$ & $0.54 \pm 0.06$ & $33.31 \pm 4.50$ \\
$\mathrm{ISO}$ & $47.95 \pm 2.70^{* *}$ & $1.089 \pm 0.001^{*}$ & $0.44 \pm 0.02^{* *}$ & $5.25 \pm 0.64^{* * *}$ & $0.51 \pm 0.10$ & $69.78 \pm 3.06^{* * *}$ \\
$\mathrm{PNFs}$ & $25.34 \pm 1.306^{\# \#}$ & $1.092 \pm 0.001^{\#}$ & $0.23 \pm 0.01^{\# \#}$ & $3.4 \pm 0.42^{\#}$ & $0.50 \pm 0.09$ & $62.12 \pm 6.22$ \\
PNFr & $33.86 \pm 5.982^{\# \#}$ & $1.091 \pm 0.001^{\#}$ & $0.31 \pm 0.05^{\# \# \#}$ & $4.2 \pm 0.40^{\#}$ & $0.50 \pm 0.10$ & $63.30 \pm 4.80$ \\
\hline
\end{tabular}

Values are expressed as average \pm standard deviation $(\mathrm{n}=3),{ }^{*}=\mathrm{p}<0.05,{ }^{* *}=\mathrm{p}<0.01, * * *=\mathrm{p}<0.001, v s$. control; ${ }^{*} \mathrm{p}<0.05,{ }^{\# \#} \mathrm{p}<0.01$, ${ }^{\# \#} \mathrm{p}<0.001$, vs. ISO group; GP = grape pomace; PNFs = fresh Pinot noir grape pomace extract; PNFr = fermented Pinot noir grape pomace extract; ISO = isoprenaline; TOS = total oxidative status; TAR = total antioxidant reactivity; OSI = oxidative stress index; $\mathrm{MDA}=$ malondialdehyde; $\mathrm{SH}=$ total thiols; $\mathrm{NOx}=$ nitrites and nitrates.

The present study performed a phytochemical analysis of the Pinot noir GP extracts, and thereafter demonstrated that the polyphenol-rich PNFs and PNFr extracts had potent antioxidant and cardioprotective effects.

It is known that grape consumption may contribute to the prophylaxis of chronic diseases such as cardiovascular diseases by reducing oxidative stress. These beneficial properties of grapes and grapes products are related to their polyphenolic content. Phenolic compounds represent a large group of natural plant products, having anti-inflammatory, antioxidant, antithrombotic, cardio-protective and vasodilator effect [30].

Pinot noir is a red wine grape. During the red winemaking process, there is an incomplete extraction of the phenolic compounds [31]. Because the phytochemical profile of GP is associated with bioactive properties, before studying the biological effects, the polyphenolic composition was analysed. Initially TPI, CT and TAC have been measured.

Both PNFs and PNFr samples had a high TPI. If compared to the total polyphenolic content in other red GP extracts there were differences related to the wine grape varieties, climate, ripeness of the grapes, and the wine production process [31]. Another factor that may influence the total phenolic content is the maceration process, TPI being higher with a longer maceration time [31]. In our study, the maceration influence may explain the higher TPI in PNFr than in PNFs samples.

In the grapes, tannins are localized mainly in the skin and seeds. There are two subgroups of tannins: the condensed tannins or proanthocyanidins (flavan3-ols monomers subunits) which are highly insoluble and hydrolysable tannins [31]. The method we used measured just the CT, which was higher in the PNFr than in the PNFs. The lower CT in PNFs are in accordance to previous reports that found that in a hydroalcoholic solution, tannin extraction from un-fermented grape skins was lower than 38\% [32]. In the present study, TAC was lower in the PNFr sample than in PNFs. About anthocyanins it is known that TAC differs between cultivars [33], and that anthocyanins accumulate in grape skin during veraison and ripening process. Thereafter, during the maceration process anthocyanins concentration lowers [34]. All these data may explain the higher TAC in the PNFs samples. 
FARMACIA, 2018, Vol. 66, 3

Although TIP, CT and TAC allowed a preliminary broad-spectrum characterization of PN GP extracts, for a better understanding, polyphenols were further identified and quantified by chromatographic methods. In PNFs and PNFr samples, proanthocyanidin were found. Their concentration increases at veraison and decreases until ripeness, and longer maceration increases the proanthocyanidin content [34]. Between PNFs and PNFr samples there were no significant differences related to the proanthocyanidin content probably due to the short maceration time. Proanthocyanidin structures differ depending of their origin, respectively in seeds there are smaller polymers made up of $(+)$-catechin, $(-)$-epicatechin, and (-)-epicatechin-3-gallate, and in skins are mainly (-)-epigallocatechin and in a much lower proportion (-)-epicatechin-3-gallate. Therefore, proanthocyanidins released from skins have a higher mean degree of polymerization (mDP), and proanthocyanidins released from seeds have a higher proportion of galloylation and a lower mDP [35]. During the maceration process the proportion of PD tends to decrease, and G\% to increase [34]. The results obtained on PN GP followed the same trend, mDP being higher in the PNFs samples and $\mathrm{G} \%$ being higher in the PNFr samples.

Flavan-3-ols concentration was higher in PNFs than in PNFr, and there was no significant difference between the content of $(+)$-catechin, (-)-epicatechin and epicatechin-3-O-gallate. These results were in accordance with previous analysis that found that, during the vinification process; flavan-3-ols were extracted from grapes, but not completely, remaining in great amount in the GP [10].

Stilbenes are among the main polyphenols involved in the health protection effects of drinking wine. Several in vitro studies have shown that resveratrol has anti-cancer, anti-oxidant, anti-inflammatory, cardioprotective and platelet anti-aggregant activity, and glycosylated stilbenes have antifungal and antioxidant effects [36]. The main grape stilbenes are cis- and trans-resveratrol, glycosylated derivatives of resveratrol cis- and trans-piceid, piceatannol and resveratrol dimers (viniferins) [36]. Like in other red GPs [14], in Pinot noir GP, resveratrol and piceid were found in the form of trans- and cis- isomers. Stilbenes concentration was higher in PNFs than PNFr. In each PN GP sample, trans-resveratrol was in lower concentrations than cis-resveratrol, and trans-piceid in higher concentration than cis-piceid. About cis-resveratrol it was reported that the extraction procedure may influence its concentration [14], and about piceid that it may be hydrolysed releasing resveratrol [37].

The antioxidant activity of plant extracts is the result of the combined effects of many different compounds. Thus, the phytochemical data provided information suggesting potential antioxidant properties for PNFs and PNFr. DPPH method was used for in vitro antioxidant activity evaluation [38]. As phenolics compounds are the most important grape secondary metabolites with antioxidant properties [39], the polyphenol content of PNFs and PNFr samples correlated with the good antioxidant activity evaluated by DPPH test. In other reports, the fermented pomace had a better DPPH RSA than the unfermented pomace [40]. In our study PNFs and PNFr had similar DPPH RSA.

It was demonstrated that some extracts exhibit antioxidant properties both in vitro and in vivo, but other studies demonstrated that the antioxidant in vitro activity does not always apply to in vivo models. Moreover, it was proved that in vitro and in vivo antioxidant effects may not correspond because polyphenols may also act as pro-oxidants via Fenton reaction [41]. Therefore, after demonstrating the promising antioxidant capacity by DPPH test, the extracts were examined in terms of their effects on experimental in vivo antioxidant and cardioprotective effects in a rat ISO-induced myocardial infarction (MI).

ISO is a synthetic catecholamine and beta-adrenergic agonist able to produce in animals structural and functional abnormalities comparable with cardiac ischemia in humans. As a consequence, in ISO group ECG showed acute ischemia changes. PNFs and PNFr pre-treatments significantly prevented the ECG abnormalities, suggesting a cardio-protective effect.

Because myocardial injury leads to loss of myocyte cell membrane integrity and increased permeability [42], the degree of AST, ALT and CK-MB leakage from myocardium correlated with the myocardial injury in ISO rats. In the present study, PNFs and PNFr pre-treatments significantly reduced leakage of myocardial enzymes as compared to MI group. These results further confirmed the cardio-protective effects of PNFs and PNFr.

Heart tissue is more vulnerable to oxidative stress because of limited antioxidant defence. Moreover, because ROS can freely cross intercellular membranes, plasma can be exposed to the harmful effect of ROS as well [43]. Furthermore, it was proved that in early MI pathophysiology oxidative stress is coupled with inflammatory responses [44]. The cardioprotective effects of tannins on ISO-induced MI were potentially associated with ROS scavenging, inflammation inhibition, cell apoptosis reduction and endothelial protection [45]. In the present study, oxidative stress was evaluated in vivo systemically by measuring serum oxidative stress biomarkers. ISO-induced MI was associated with a significant systemic oxidative stress, characterized by increased serum TOS, OSI, NO and MDA, and depletion of TAR. 
Some experimental studies have shown that protective antioxidant therapy was based on early normalization of intracellular events linked to the progression of oxidative damage [43]. In this respect, in the present study we demonstrated that PNFs and PNFr pretreatments reduced oxidative stress by lowering serum TOS and OSI, and elevating TAR. Furthermore, PNFs and PNFr pre-treatments decreased serum MDA, the lipid peroxidation end product. Together, all these results suggested that PNFs and PNFr pretreatments have antioxidant potential. Other red grape pomace hydroalcoholic extract had also antioxidative and anti-inflammatory effects [2].

Nitric oxide (NO) is an important signalling molecule generated from L-arginine by endothelial, neural and inducible nitric oxide synthase (iNOS). When generated at a low concentration for a brief period, $\mathrm{NO}$ is part of host defence mechanism, whereas the excessive or prolonged induction of NO is involved in pathological processes associated with oxidative stress and inflammation [46]. In the present study ISO-induced MI was associated with NOx increase. Previous studies have postulated that ISO-induced generation of NO through increased expression of iNOS could be an important factor involved into MI pathophysiology [46]. In rats, MI pre-treatment with reduced dose of vitamin $\mathrm{C}$ as antioxidant was able to suppress iNOS synthesis in myocardium [44]. Preconditioning myocardium with resveratrol has been shown to be related to the stimulation of iNOS [47]. PNFs and PNFr pre-treatments had no important effect on NOx concentration because it could not prevent NO increase after ISO administration. Although enhanced peroxynitrite formation contributes to the patho-physiology of cardiovascular diseases, it was demonstrated that nanomolar concentrations of peroxynitrite inhibits leukocyte-endothelial cell interaction, which improves post-ischemic myocardial function [48].

\section{Conclusions}

This report demonstrated that grape pomace from Pinot noir can be considered a rich source of polyphenolic compounds having in vitro antioxidant activities. The results also indicate that there are differences among PN grape pomace samples, fermented grape pomace having a higher polyphenols concentration. We also found that in vivo pre-treatment with Pinot noir grape pomace extracts had cardio-protective effects in rat ISO-induced myocardial injury by reducing oxidative stress. Future studies should analyse Pinot noir GP extracts effects on oxidative stress associated with other pathological conditions. This study contributes to the development of grapes by-products valorisation and may offer an alternative to reduce environmental contamination.

\section{Conflicts of Interest}

The authors declare no conflicts of interest in the present study.

\section{References}

1. Fontana AR, Antoniolli A, Bottini R, Grape pomace as a sustainable source of bioactive compounds: Extraction, characterization, and biotechnological applications of phenolics. J Agric Food Chem., 2013; 61: 8987-9003.

2. Gonçalves GA, Soares AA, Correa RCG, Barros L, Haminiuk CWI, Peralta RM, Merlot grape pomace hydroalcoholic extract improves the oxidative and inflammatory states of rats with adjuvant-induced arthritis. J Funct Foods, 2017; 33: 408-418.

3. Delaquis PJ, Mazza G, Antimicrobial properties of isothiocyanates in food preservation. Food Technol., 1995; 49: 73-84.

4. Fanzone M, Zamora F, Jofré V, Assof M, GómezCordovés C, Peña-Neira Á, Phenolic characterisation of red wines from different grape varieties cultivated in Mendoza province (Argentina). J Sci Food Agric., 2012; 92: 704-718.

5. Pertuzatti PB, Barcia MT, Rodrigues D, Da Cruz PN, Hermosín-Gutiérrez I, Smith R, Antioxidant activity of hydrophilic and lipophilic extracts of Brazilian blueberries. Food Chem., 2014; 164: 81-88.

6. Pîrvu L, Sha'at F, Miclea LC, Savopol T, Neagu G, Udeanu DI, Moisescu MG, Polygonum bistorta L. herba et flores. Polyphenols profile, antioxidant properties and cytotoxic effect on murine fibroblast cell line NIH3T3. Farmacia, 2017; 65(4): 571-576.

7. Oliveira-Sales EB, Dugaich AP, Carillo BA, Abreu NP, Boim MA, Martins PJ, Oxidative stress contributes to renovascular hypertension. Am J Hypertens., 2008; 21: 98-104.

8. Cătoi AF, Pârvu A, Mureşan A, Busetto L, Metabolic Mechanisms in Obesity and Type 2 Diabetes: Insights from Bariatric/Metabolic Surgery. Obesity Facts, 2015; 350-363.

9. Cătoi AF, Pârvu A, Galea RF, Pop ID, Mureşan A, Cătoi $\mathrm{C}$, Nitric oxide, oxidant status and antioxidant response in morbidly obese patients: The impact of 1-year surgical weight loss. Obes Surg., 2013; 23: 1858-1863.

10. Lingua MS, Fabani MP, Wunderlin DA, Baroni MV, In vivo antioxidant activity of grape, pomace and wine from three red varieties grown in Argentina: Its relationship to phenolic profile. $J$ Funct Foods, 2016; 20: 332-345.

11. Antoniolli A, Fontana AR, Piccoli P, Bottini R, Characterization of polyphenols and evaluation of antioxidant capacity in grape pomace of the $\mathrm{cv}$. Malbec. Food Chem., 2015; 178: 172-178.

12. Ho E, Karimi Galougahi K, Liu CC, Bhindi R, Figtree GA, Biological markers of oxidative stress: Applications to cardiovascular research and practice. Redox Biol., 2013; 1: 483-491.

13. Vaisman N, Niv E, Daily consumption of red grape cell powder in a dietary dose improves cardiovascular parameters: a double blind, placebo-controlled, 
FARMACIA, 2018, Vol. 66, 3

randomized study. Int J Food Sci Nutr., 2015; 66: 342-349.

14. Teixeira A, Baenas N, Dominguez-Perles R, Barros A, Rosa E, Moreno DA, Natural bioactive compounds from winery by-products as health promoters: A review. Int J Mol Sci., 2014; 15: 15638-15678.

15. Drózdz P, Sežiene V, Wójcik J, Pyrzyńska K, Evaluation of bioactive compounds, minerals and antioxidant activity of lingonberry (Vaccinium vitisidaea L.) Fruits. Molecules, 2018; 23: E53.

16. Ribéreau-Gayon P, Glories Y, Maujean A, Dubourdieu D, Handbook of Enology. Handbook of Enology. 2006.

17. Sarneckis CJ, Dambergs RG, Jones P, Mercurio M, Herderich MJ, Smith PA, Quantification of condensed tannins by precipitation with methyl cellulose: Development and validation of an optimised tool for grape and wine analysis. Aust J Grape Wine Res., 2006; 12: 39-49.

18. Bakker J, Timberlake CF, The distribution and content of anthocyanins in young port wines as determined by high performance liquid chromatography. $J \mathrm{Sci}$ Food Agric., 1985; 36: 1325-1333.

19. Kennedy JA, Jones GP, Analysis of proanthocyanidin cleavage products following acid-catalysis in the presence of excess phloroglucinol. J Agric Food Chem., 2001; 49: 1740-1746.

20. Lago-Vanzela ES, Da-Silva R, Gomes E, GarcíaRomero E, Hermosín-Guti I, Phenolic Composition of the Brazilian Seedless Table Grape Varieties. $J$ Agric Food Chem., 2011; 59: 8314-8323.

21. Castillo-Munoz N, Gomez-Alonso S, Garcia-Romero E, Gomez MV, Velders A, Hermosin-Gutierrez I, Flavonol 3-O-Glycosides Series of Vitis vinifera cv. Petit Verdot Red Wine Grapes. J Agric Food Chem., 2009; 57: 209-219.

22. Choudhury JD, Sharma D, Mayank V, Behera SHS, Evaluation of Antioxidant Activity of Ethanolic Extract of Ocimum canum in prevention of Renal Ischemia. Int J Pharm Sci Res., 2012; 3: 3259-3266.

23. Parvu AE, Parvu M, Vlase L, Miclea P, Mot AC, Silaghi-Dumitrescu R, Anti-inflammatory effects of Allium schoenoprasum L. leaves. J Physiol Pharmacol., 2014; 65: 309-315.

24. Farshid AA, Tamaddonfard E, Moradi-Arzeloo M, Mirzakhani N, The effects of crocin, insulin and their co-administration on the heart function and pathology in streptozotocin-induced diabetic rats. Avicenna J Phytomed., 2016; 6: 658-670.

25. Erel O, A new automated colorimetric method for measuring total oxidant status. Clin Biochem., 2005; 38: 1103-1111.

26. Erel $\mathrm{O}, \mathrm{A}$ novel automated method to measure total antioxidant response against potent free radical reactions. Clin Biochem., 2004; 37: 112-119.

27. Porfire AS, Leucuţa SE, Kiss B, Loghin F, Pârvu AE, Investigation into the role of $\mathrm{Cu} / \mathrm{Zn}$-SOD delivery system on its antioxidant and antiinflammatory activity in rat model of peritonitis. Pharmacol Reports, 2014; 66: 670-676.

28. Draper HH, Squires EJ, Mahmoodi H, Wu J, Agarwal S, Hadley M, A comparative evaluation of thiobarbituric acid methods for the determination of malondi aldehyde in biological materials. Free Radic Biol Med., 1993; 15: 353-363.
29. Oniga S, Pârvu AE, Tiperciuc B, Palage M, Oniga O, The study of the anti-inflammatory activity of some thiazolyl- $\Delta 21,3,4$ oxadiazolines and 5-carboxiethyl2-hydrazon-4-methyl- thiazole-derivatives. Farmacia. 2011; 59(1): 44-50.

30. Haminiuk CWI, Maciel GM, Plata-Oviedo MSV, Peralta RM, Phenolic compounds in fruits - an overview. Int J Food Sci Technol., 2012; 47: 20232044.

31. $\mathrm{Xu} \mathrm{Y,} \mathrm{Burton} \mathrm{S,} \mathrm{Kim} \mathrm{C,} \mathrm{Sismour} \mathrm{E,} \mathrm{Phenolic}$ compounds, antioxidant, and antibacterial properties of pomace extracts from four Virginia-grown grape varieties. Food Sci Nutr., 2016; 4: 125-133.

32. Fournand D, Vicens A, Sidhoum L, Souquet JM, Moutounet M, Cheynier V, Accumulation and extractability of grape skin tannins and anthocyanins at different advanced physiological stages. J Agric Food Chem., 2006; 54: 7331-7338.

33. Li Y, Ma R, Xu Z, Wang J, Chen T, Chen F, Identification and quantification of anthocyanins in Kyoho grape juice-making pomace, Cabernet Sauvignon grape winemaking pomace and their fresh skin. J Sci Food Agric., 2013; 93: 1404-1411.

34. Gil M, Kontoudakis N, González E, Esteruelas M, Fort F, Canals JM, Influence of Grape maturity and maceration length on color, polyphenolic composition, and polysaccharide content of Cabernet Sauvignon and Tempranillo Wines. J Agric Food Chem., 2012; 60: 7988-8001.

35. Gil M, Esteruelas M, González E, Kontoudakis N, Jiménez J, Fort F, Effect of two different treatments for reducing grape yield in Vitis vinifera cv Syrah on wine composition and quality: Berry thinning versus cluster thinning. J Agric Food Chem., 2013; 61: 4968-4978.

36. Flamini R, Mattivi F, De Rosso M, Arapitsas P, Bavaresco L, Advanced knowledge of three important classes of grape phenolics: Anthocyanins, stilbenes and flavonols. Int J Mol Sci., 2013; 14: 19651-19669.

37. Potdar S, Parmar MS, Ray SD, Cavanaugh JE, Protective effects of the resveratrol analog piceid in dopaminergic SH-SY5Y cells. Arch Toxicol., 2017; 92: 669-677.

38. Alam MN, Bristi NJ, Rafiquzzaman M, Review on in vivo and in vitro methods evaluation of antioxidant activity. Saudi Pharm J., 2013; 21: 143-152.

39. Beres C, Costa GNS, Cabezudo I, da Silva-James NK, Teles ASC, Cruz APG, Towards integral utilization of grape pomace from winemaking process: A review. Waste Manag., 2017; 68: 581-594.

40. Albuquerque JGF, Assis VL, Almeida AJPO, Basílio IJLD, Luciano MN, Meireles BRLA, Antioxidant and vasorelaxant activities induced by northeastern Brazilian fermented grape skins. BMC Complement Altern Med., 2017; 17: 376.

41. Veskoukis AS, Kyparos A, Nikolaidis MG, Stagos D, Aligiannis N, Halabalaki M, The antioxidant effects of a polyphenol-rich grape pomace extract in vitro do not correspond in vivo using exercise as an oxidant stimulus. Oxid Med Cell Longev., 2012; 2012: 185867.

42. Mohanty IR, Arya DS, Dinda A, Gupta SK, Comparative cardioprotective effects and mechanisms of vitamin $\mathrm{E}$ and lisinopril against ischemic reperfusion 
induced cardiac toxicity. Environ Toxicol Pharmacol., 2013; 35: 207-217.

43. Taskin E, Kindap EK, Ozdogan K, Aycan MBY, Dursun N, Acute adriamycin-induced cardiotoxicity is exacerbated by angiotension II. Cytotechnology, 2016; 68: 33-43.

44. Dallak M, A synergistic protective effect of selenium and taurine against experimentally induced myocardial infarction in rats. Arch Physiol Biochem., 2017; 123 : 344-355.

45. Hu X, Wang H, Lv X, Chu L, Liu Z, Wei X, Cardioprotective Effects of Tannic Acid on IsoproterenolInduced Myocardial Injury in Rats: Further Insight into "French Paradox". Phyther Res., 2015; 29: 1295-1303.
46. Ribeiro DA, Buttros JB, Oshima CTF, Bergamaschi CT, Campos RR, Ascorbic acid prevents acute myocardial infarction induced by isoproterenol in rats: role of inducible nitric oxide synthase production. $J$ Mol Histol., 2009; 40: 99-105.

47. Imamura G, Bertelli AA, Bertelli A, Otani H, Maulik N, Das DK, Pharmacological preconditioning with resveratrol: an insight with iNOS knockout mice. $A m J$ Physiol Hear Circ Physiol., 2002; 1110: 1996-2003.

48. Lefer DJ, Scalia R, Campbell B, Nossuli T, Hayward R, Salamon M, Peroxynitrite Inhibits leukocyte endothelial cell interactions and protects against ischemia-reperfusion injury in rats. Society, 1997; 99: 684-691. 